\section{Topical Intrapocket Anesthesia During Scaling and Root Planing: a Randomized Clinical Trial}

Raquel Pippi Antoniazzi', Bruna Cargnelutti', Daniela Napoleão Freitas², Magáli Beck Guimarães ${ }^{1}$, Fabricio Batistin Zanatta ${ }^{2}$, Carlos Alberto Feldens ${ }^{3}$

\author{
'Dental School, Franciscan University \\ Center, Santa Maria, RS, Brazil \\ ${ }^{2}$ Postgraduate Program in Dentistry, \\ UFSM - Federal University of \\ Santa Maria, Santa Maria, \\ RS, Brazil \\ ${ }^{3}$ Postgraduate Program in Dentistry, \\ ULBRA - Lutheran University \\ of Brazil, Canoas, RS, Brazil
}

Correspondence: Dra. Raquel Pippi Antoniazzi, Rua Silva Jardim, 1175, 97010-491 Santa Maria, RS, Brasil. Tel: +55-55-3025-1202. e-mail: raquelantoniazzi@hotmail.com

Key Words: local anesthesia, periodontitis, root planing, pain.

\section{Introduction}

It is often necessary to use anesthesia during subgingival scaling and root planing (SRP) to control pain and discomfort (1). An injectable anesthetic is considered the gold standard in such cases and may or may not be used in conjunction with a topical anesthetic (2). While injectable anesthetics are effective in controlling pain, many patients report fear of the needle, long-lasting effects and the prolonged numbness of adjacent tissues, such as the lips and tongue (3-5). The need for painless, noninvasive, fast-acting anesthetics with effectiveness only during the procedure has led to the investigation of the use of substances with topical application during SRP (3,6-11) and periodontal maintenance (12). It has recently been demonstrated that the use of a topical anesthetic does not compromise subgingival treatment and offers similar benefits to pocket probing and clinical attachment gain to an injectable anesthetic (13).

Oraqix ${ }^{\circledast}$ is a topical anesthetic containing lidocaine $(25 \mathrm{mg} / \mathrm{g}$ ) and prilocaine $(25 \mathrm{mg} / \mathrm{g})$ that is commercially available as an anesthetic for subgingival SRP. This product has proven to be a reliable alternative to injectable anesthesia (7-9). A eutectic mixture denominated $\mathrm{EMLA}^{\odot}$ has the same composition as Oraqix, but is offered at a lower cost. To date, no studies have compared the efficacy of EMLA to another inexpensive, commonly used anesthetic ( $2 \%$ benzocaine) during subgingival SRP procedures. Moreover, few studies have compared the effects of EMLA to injectable anesthesia using pain scores for the purposes of evaluation.

The study hypothesis is that topical anesthetics are equivalent to injectable anesthetic regarding the control of pain during SRP. The aim of the present study was to compare the effects of EMLA, injectable 2\% lidocaine, topical $2 \%$ benzocaine and a placebo substance on reducing pain during subgingival scaling and root planing.

\section{Material and Methods}

\section{Study Design and Subjects}

A masked, randomized clinical trial with a split-mouth design was carried out. Forty-one patients were recruited from the Dental School of the Franciscan University Center, Santa Maria, RS, Brazil, from June 2010 to March 2012. This study received approval from the Human Research Ethics Committee of the university and all participants signed a statement of informed consent. The registration number is NCT01860235 (www.clinicaltrials.gov).

For gingivitis treatment, all patients received two 
to four supragingival scaling and polishing sessions and meticulous self-care oral hygiene training. After treatment and the achievement of the goal of a low percentage of visible plaque and gingival bleeding $(<15 \%)$, an examination was performed for the assessment of probing depth (PD), clinical attachment level (CAL) and bleeding on probing (BOP) at six sites per tooth to determine the sites that required SRP treatment. Eligible individuals were selected from those requiring SRP with at least two teeth in four sextants with $\geq 1$ site with PD and CAL $\geq 5 \mathrm{~mm}$ and BOP following treatment for gingivitis (without marginal bleeding). The other inclusion criteria were aged 18 years or older, adequate understanding of the pain scales employed and no history of previous periodontal treatment. The following were the exclusion criteria: history of allergies or sensitivity reaction to any amide or ester anesthetic; having received anesthesia or sedation $12 \mathrm{~h}$ prior to SRP; be using pain medication (i.e., sedative, muscle relaxant, anti-inflammatory medication, and narcotic analgesic); ulcerations or abscesses in the oral cavity; oral disease with immediate need for surgery; history of alcohol abuse; current pregnancy; uncontrolled hypertension; and participation in a clinical trial of an investigational drug within four months after the onset of the present study.

\section{Experimental Design}

Figure 1 displays the flow chart of the study. After the clinical parameters had been recorded, the four sextants containing teeth with the deepest PD were chosen to participate in the experiment. Treatment with SRP was performed over six weekly sessions with the experimental procedures being conducted during the first four sessions. Therefore all patients received the four interventions. The two teeth with the deepest PD were selected from each sextant. Following the treatment of those teeth and administration of the pain scales, SRP was performed on other teeth in the sextant that required the procedure using the same type of anesthetic.

Randomization was conducted by a researcher not involved in the eligibility and entry of subjects into the study to warrant treatment allocation concealment. Block randomization was performed for the allocation of the participants to the different groups: injectable $2 \%$ lidocaine with epinephrine 1:100,000 (Alphacaine; DFL, Rio de Janeiro, RJ, Brazil); topical 5\% eutetic mixture of $25 \mathrm{mg} / \mathrm{g}$ of lidocaine and $25 \mathrm{mg} / \mathrm{g}$ of prilocaine (EMLA; AstraZeneca, Cotia, SP, Brazil); topical $200 \mathrm{mg} / \mathrm{g}$ of 2\% benzocaine (Benzotop; DFL) or a placebo substance with same appearance and viscosity as the topical anesthetics. One set of opaque envelopes contained a card stipulating the sextant to undergo treatment and a second set of envelopes contained a card stipulating the type of anesthesia to be administered. Each participant received an envelope from each set immediately prior to the start of the subgingival SRP session.

The technique used for injectable anesthesia was nerve block with at most two anesthetic cartridges per session SRP. When a topical substance was administered, the patient was masked to the type. All anesthetics were administered by the same operators (BC and DNF). Prior to administration, relative isolation was performed with cotton rolls. The selected anesthetic was applied to the

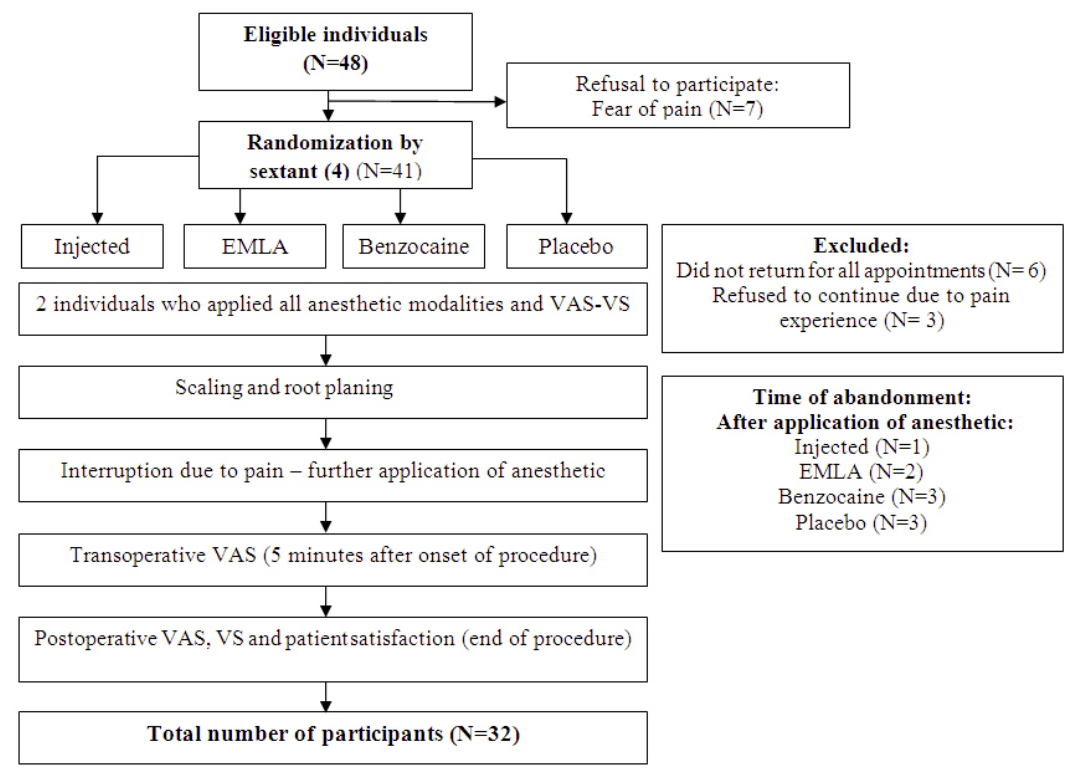

Figure 1. Study flow chart. 
two teeth with a deepest PD and BOP (regardless of the severity of PD). For topical anesthetics, the maximum dose used in the sextant was $2.5 \mathrm{~mL}$. The anesthetic was applied directly into the periodontal pocket of each tooth with a millimeter syringe and a blunt needle and inserted until overflowing the gingival margin.

Different operators performed the subgingival SRP and assessment of the main outcome. The operator who performed the subgingival SRP was blinded to the type of anesthesia to ensure that the procedure was performed similarly in all groups. For the operators masked were put under the clinic table all anesthetic types and it was requested him/her to walked away from dental chair until that was completed the anesthesia so that operator does not know the type of anesthesia that was administered. Two minutes after administration of the anesthetic administration, the operator began the SRP procedure in the sextant using curettes and periodontal files (Neumar, São Paulo, SP, Brazil). For each tooth, the patient was asked to indicate the intensity of pain experienced during the operation with the aid of a visual analog scale (VAS) five min after the onset of the procedure (VAStrans) and immediately following the procedure (VASpost). At the end of the procedure, the patient was also asked to describe the pain using a verbal scale (VS): no pain (0), mild pain (1), moderate pain (2), severe pain (3) or extremely severe pain (4). Both scales were scored in the absence of the operator $\approx$ that had performed the subgingival SRP. In the occurrence of pain during the procedure, an additional dose of the same anesthetic was administered. If pain persisted after this second application, injectable nerve-block anesthesia was administered. All information was recorded on the patient charts. Subgingival SRP was performed until the root surfaces achieved adequate smoothness. The duration of the procedure on the selected teeth was also recorded. Patient satisfaction with the anesthesia was determined at the end of all treatment sessions using the following four categories: very satisfied, satisfied, dissatisfied and very dissatisfied.

When the patients returned for the next treatment session, they were asked about the occurrence of pain, discomfort, localized ulceration, edema or flaking of the oral mucosa.

\section{Intra-examiner and Inter-examiner Reproducibility}

Prior to the main study, two examiners underwent a training and calibration exercise for the determination of reliability regarding the periodontal variables and administration of the anesthetics and pain scales. Five patients were used for the determination of intra-examiner and inter-examiner reliability regarding the PD and CAL measures. Agreement was determined using the weighted kappa (K) statistic. K values for intra-examiner agreement regarding PD and CAL were 0.79 and 0.76 for Examiner 1 and 0.74 and 0.80 for Examiner 2, respectively. $K$ values for inter-examiner agreement were 0.75 and 0.78 for PD and $\mathrm{CAL}$, respectively. Both intra-examiner and inter-examiner reliability were determined a second time eight months after the onset of the study and all $\mathrm{K}$ values were $\geq 0.8$.

\section{Sample Size}

The sample size was calculated based on a clinically relevant difference in VAS scores $(15 \mathrm{~mm})$ between groups with a standard deviation (SD) of $25 \mathrm{~mm}$. Considering a significance level of 5\%, 90\% study power and the paired design, it was determined that a minimum of 31 patients were needed for each group. This number was increased to 41 patients to compensate for a possible $25 \%$ dropout rate.

\section{Data Analysis}

Data were analyzed using the Statistical Package for Social Sciences (SPSS), version 20.0.0. The Shapiro-Wilk test was used to determine the normality of distribution. As normal distribution was demonstrated, the data were expressed as mean and standard deviation values. Repeatedmeasures analysis of variance, chi-squared test and Tukey's post-hoc test were used for the comparisons of the groups $(p<0.05)$. Spearman correlation coefficients were calculated to determine the strength of the correlation between the VAS and VS. Poisson regression with robust variance was performed to compare patient dissatisfaction with different anesthetic modalities.

\section{Results}

Among the 41 individuals enrolled, nine did not complete the study. The reasons and the timing for the dropouts are specified in Figure 1. Mean age of participants was $49.4 \pm 9.4$ years. Table 1 displays the PD and CAL values after gingivitis treatment and operating time ( $\mathrm{min}$ ). The average time required for root planing of two teeth was approximately 60 min. No statistically significant differences among groups were found for these variables. Further analysis showed no statistically significant differences in the allocation sequence of anesthesia modalities between individual participants $(p=0.78)$.

Table 2 displays the VAStrans, VASpost (0 to $100 \mathrm{~mm}$ ) and VS score among the different groups. Regarding VAStrans, a significantly lower score was found with injectable $2 \%$ lidocaine in comparison to the benzoncaine and placebo groups and a lower score was found in the EMLA group in comparison to the placebo group. Significantly lower VASpost and VS scores were found in the injectable $2 \%$ lidocaine and EMLA groups in comparison to the $2 \%$ benzocaine and placebo groups. Most patients receiving 
injectable 2\% lidocaine (87.5\%) and EMLA (84.4\%) reported no pain or mild pain during subgingival SRP. In contrast, approximately half $(53.1 \%)$ of the patients receiving benzocaine and two thirds (71.8\%) of those receiving placebo experienced at least moderate pain (Fig. 2).

Approximately $72 \%$ of patients required a second anesthetic application when exposed to the placebo, while a significantly lower percentage (37.5\%) of patients receiving EMLA had to be re-anesthetized. In addition, more than $90 \%$ of patients receiving EMLA, $75 \%$ of patients receiving benzocaine and $50 \%$ of patients receiving placebo did not require injectable anesthesia (Table 3 ).

Most individuals reported satisfaction with the injectable anesthetic and EMLA during subgingival SRP. In contrast, more than half (59.4\%) of the patients receiving benzocaine and nearly two thirds (65.7\%) of those receiving placebo felt dissatisfied with the anesthetic. The multivariable model showed that patient dissatisfaction with benzocaine anesthesia and placebo was approximately 10 times greater than injectable anesthetics, even after adjustment for gender, age, operative time and PD. (Table 4). No significant difference in patient dissatisfaction was detected between EMLA and injectable anesthetic.

Strong correlations were found between the responses of the VAS and VS for nearly all anesthetic procedures $(\rho=0.841 ; p<0.0001)$.

Most individuals reported no adverse effects from the different anesthetics tested, such as pain, discomfort, ulceration, edema or flaking. Two patients who received benzocaine and three who received EMLA reported numbness in the glottis region, but did not report any discomfort or dissatisfaction. However, as demonstrated in the flow chart, one patient in the benzocaine group and

Table 1. Probing depth (PD), clinical attachment level (CAL) and operating time (OT) for different anesthetic modalities

\begin{tabular}{|c|c|c|c|}
\hline \multirow{2}{*}{$\begin{array}{l}\text { Anesthetic } \\
\text { modality }\end{array}$} & $\mathrm{PD}(\mathrm{n}=41)$ & $\begin{array}{c}\text { CAL } \\
(\mathrm{n}=41)\end{array}$ & $\begin{array}{c}\text { OT } \\
(n=32)\end{array}$ \\
\hline & $\begin{array}{c}\text { Mean } \\
\text { (min-max) }\end{array}$ & $\begin{array}{c}\text { Mean } \\
(\min -\max )\end{array}$ & $\begin{array}{c}\text { Mean } \\
\text { (SD) }\end{array}$ \\
\hline $\begin{array}{l}\text { Injectable } \\
2 \% \text { lidocaine }\end{array}$ & $\begin{array}{c}4.55 \\
(3.29-7.45)\end{array}$ & $\begin{array}{c}5.34 \\
(3.34-8.33)\end{array}$ & $\begin{array}{c}53.06 \pm \\
29.66\end{array}$ \\
\hline EMLA & $\begin{array}{c}4.25 \\
(3.35-6.98)\end{array}$ & $\begin{array}{c}4.89 \\
(3.35-7.10)\end{array}$ & $\begin{array}{c}60.06 \pm \\
36.52\end{array}$ \\
\hline $\begin{array}{l}\text { Topical 2\% } \\
\text { benzocaine }\end{array}$ & $\begin{array}{c}4.25 \\
(3.24-7.47)\end{array}$ & $\begin{array}{c}4.96 \\
(3.75-8.64)\end{array}$ & $\begin{array}{c}61.25 \pm \\
36.32\end{array}$ \\
\hline Placebo & $\begin{array}{c}4.36 \\
(3.29-6.45)\end{array}$ & $\begin{array}{c}4.96 \\
(3.69-7.75)\end{array}$ & $\begin{array}{c}61.18 \pm \\
32.51\end{array}$ \\
\hline$p$ value & $\mathrm{p}=0.32^{*}$ & $\mathrm{p}=0.12^{*}$ & $p=0.73^{*}$ \\
\hline
\end{tabular}

*Repeated-measures ANOVA. two patients in the placebo group left the study due to the pain they experienced after the SRP procedure.

\section{Discussion}

It is well accepted that injectable anesthesia is the first choice for routine SRP procedures $(2,14)$. However, needles are associated with pain, anxiety and fear $(1,4)$. As a result, some patients prefer mild or moderate pain during SRP rather than receiving an injection (3). In the present study, EMLA was found to provide topical anesthetic effectiveness similar to injectable lidocaine and better than topical benzocaine or a placebo substance. However, in the EMLA group, anesthesia had to be repeated in almost half of the patients to be effective.

A number of studies evaluating topical intrapocket anesthesia have used Oraqix, which was developed for

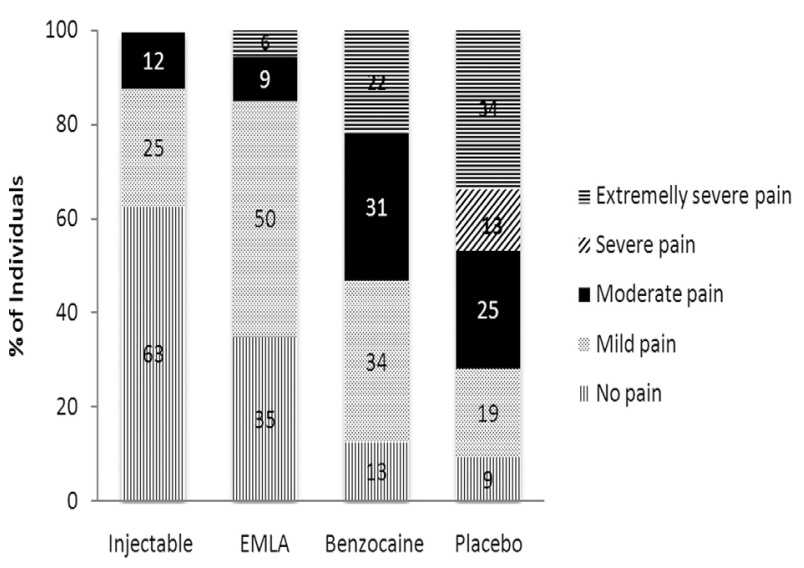

Figure 2. Percentage of patients according to VS pain scores for different anesthetics.

Table 2. VAStrans, VASpost and VS for different anesthetic modalities (mean $\pm 95 \% \mathrm{Cl})(\mathrm{n}=32)$

\begin{tabular}{lccc}
\hline $\begin{array}{l}\text { Anesthetic } \\
\text { modality }\end{array}$ & $\begin{array}{c}\text { VAS } \\
\text { trans-operative }\end{array}$ & $\begin{array}{c}\text { VAS } \\
\text { postoperative }\end{array}$ & VS \\
\hline $\begin{array}{l}\text { lnjectable } \\
2 \% \text { lidocaine }\end{array}$ & $\begin{array}{c}11.32 \\
(5.72-16.92)^{\mathrm{a} \#}\end{array}$ & $\begin{array}{c}13.59 \\
(8.89-18-30)^{\mathrm{a}}\end{array}$ & $\begin{array}{c}0.47 \\
(0.23-0.70)^{\mathrm{a}}\end{array}$ \\
EMLA & 21.00 & 24.77 & 0.89 \\
& $(13.55-28.50)^{\mathrm{ab}}$ & $(16.67-32.86)^{\mathrm{a}}$ & $(0.56-1.21)^{\mathrm{a}}$ \\
Topical 2\% & 33.10 & 41.54 & 1.75 \\
benzocaine & $(24.57-41.63)^{\mathrm{bc}}$ & $(31.64-51.44)^{\mathrm{b}}$ & $(1.33-2.17)^{\mathrm{b}}$ \\
Placebo & 48.91 & 60.31 & 2.30 \\
& $(38.37-59.46)^{\mathrm{c}}$ & $(49.27-71.36)^{\mathrm{c}}$ & $(1.82-2.78)^{\mathrm{b}}$ \\
$\mathrm{p}$ value & $\mathrm{p}<0.0001^{*}$ & $\mathrm{p}<0.0001^{*}$ & $\mathrm{p}<0.0001^{*}$ \\
\hline
\end{tabular}

*Repeated-measures ANOVA/ \#Tukey's post-hoc test. a-b: significant differences; a-a and b-b and c-c: without significant differences. 
periodontal use and has demonstrated satisfactory effectiveness for subgingival SRP (3,7-9). Oraqix was found to be safe and effective at doses ranging from $3.5 \mathrm{~g} \mathrm{(2.5}$ $\mathrm{mL})(15)$ to $8.5 \mathrm{~g}(6 \mathrm{~mL})(16)$ per session of subgingival SRP. Studies have demonstrated the superior effect of EMLA in comparison to placebo substances in reducing discomfort of during dental procedures $(11,17-19)$. EMLA also results in less pain and discomfort during treatment for mild chronic periodontitis in comparison to a placebo (11), with similar results as those obtained with a lidocaine adhesive and both anesthetics have proven better than electronic anesthesia in reducing pain during subgingival SRP (10). Moreover, EMLA significantly reduces pain during SRP with manual curettes and ultrasonic scalers in comparison to manual curettes alone without any anesthetic modality (6). The present findings are in agreement with these data and provide additional information, as this study offers a comparison of the effectiveness of EMLA, injectable 2\% lidocaine, topical benzocaine and a placebo substance.

Pain intensity is often assessed using a VAS or VS (20). In the present study, the VAS was always used before the VS to avoid the influence of the verbal statement expressed with the latter. A VAS is useful for comparing pain in the same

Table 3. Percentage of subjects receiving second anesthesia application and injectable anesthesia in different anesthetic groups

\begin{tabular}{lcc}
\hline Anesthetic modality & $\begin{array}{c}2^{\text {nd }} \text { anesthetic } \\
\text { application } \\
\text { requirement (\%) }\end{array}$ & $\begin{array}{c}\text { Injectable } \\
\text { anesthetic } \\
\text { requirement (\%) }\end{array}$ \\
\hline Injectable 2\% lidocaine & 0 & - \\
EMLA & $37.50^{\text {a\# }}$ & $6.25^{\mathrm{a}}$ \\
Topical 2\% benzocaine & $53.10^{\mathrm{ab}}$ & $25^{\mathrm{a}}$ \\
Placebo & $71.80^{\mathrm{b}}$ & $50^{\mathrm{b}}$ \\
$\mathrm{p}$ value & $\mathrm{p}=0.005^{*}$ & $\mathrm{p}=0.001^{*}$ \\
\hline
\end{tabular}

*Chi-squared test/\#Tukey's post-hoc test. a-b: significant differences; $\mathrm{a}-\mathrm{a}$ and b-b: without significant differences. individual (20). Both scales demonstrated that injectable anesthesia and EMLA resulted in lesser pain during the SRP procedures in comparison to the other methods tested. Moreover, no differences were found between EMLA and injectable lidocaine. No previous study has compared these two products using on pain scales. Van Steenberghe et al. (3) found that injectable anesthetics led to lesser pain in comparison to a heat-activated gel with the same composition as EMLA. Nonetheless, $70 \%$ of the patients in the study preferred the topical anesthesia due to the lesser discomfort, duration and numbness in surrounding tissues, which are inherent characteristics of injectable anesthesia and can affect activities of daily living. Moreover, patients undergoing periodontal maintenance also prefer a topical anesthesia $(12,21)$. These findings may also explain the satisfaction with EMLA found in the present study. Notably, 12 individuals having received the injectable anesthetic reported mild to moderate pain, which may have been due to confounding the pain sensation with discomfort during the SRP procedure (2).

The VS scores revealed that patients treated with $2 \%$ benzocaine or placebo felt more pain than patients treated with EMLA and injectable lidocaine, suggesting that EMLA is a suitable anesthetic. These findings are in agreement with previous data showing that patients treated with lidocaine and prilocaine experience less pain than patients receiving a placebo substance, using a VS for pain assessment (7$9,11)$. Moreover, strong correlation was found between the results of the VAS and VS, which is also in agreement with data described in a previous study (10).

Approximately $72 \%$ of the placebo group required a second topical anesthetic during SRP compared to $37.5 \%$ of patients in the EMLA group. Moreover, $50 \%$ of patients who received the placebo, 25\% who received benzocaine and $6.2 \%$ who received EMLA reported pain intolerance after the second administration topical anesthesia. These findings are in agreement with previous studies comparing a 5\% anesthetic gel with placebo (7-9). However, one study

Table 4. Prevalence, unadjusted and adjusted prevalence ratios (PR) of dissatisfaction among participants according to the anesthetic modalities. Poisson regression analysis

\begin{tabular}{|c|c|c|c|c|c|c|c|}
\hline \multirow{2}{*}{ Anesthetic modality } & \multirow{2}{*}{$\mathrm{N}$} & \multicolumn{2}{|c|}{ Patient dissatisfaction* } & \multirow{2}{*}{$\begin{array}{l}\text { PR }(95 \% \mathrm{Cl}) \\
\text { Unadjusted }\end{array}$} & \multirow{2}{*}{$\mathrm{p}$} & \multirow{2}{*}{$\begin{array}{l}\text { PR }(95 \% \text { Cl) } \\
\text { Adjusted }^{* *}\end{array}$} & \multirow{2}{*}{$\mathrm{p}$} \\
\hline & & $\mathrm{n}$ & $(\%)$ & & & & \\
\hline Injectable $2 \%$ lidocaine & 32 & 2 & $(6.3)^{\mathrm{a}}$ & 1,0 & & 1.0 & \\
\hline EMLA & 32 & 6 & $(18.8)^{\mathrm{a}}$ & $3.0(0.6-13.7)$ & 0.158 & $2.9(0.6-13.2)$ & 0.158 \\
\hline Topical 2\% benzocaine & 32 & 19 & $(59.4)^{\mathrm{b}}$ & $9.5(2.4-37.4)$ & 0.001 & $9.8(2.5-38.4)$ & 0.001 \\
\hline Placebo & 32 & 21 & $(65.7)^{\mathrm{b}}$ & $10.5(2.6-41.1)$ & 0.001 & $10.5(2.7-40.6)$ & 0.001 \\
\hline
\end{tabular}

*Z-test with $\mathrm{p}$ adjusted by Bonferroni test: a-b: significant differences; a-a and b-b: without significant differences. ${ }^{* *}$ Adjusted for gender, age, operative time and probing pocket. 
compared EMLA with electronic anesthesia and a lidocaine adhesive and no patient required a second application of either topical or injectable anesthesia (10).

The present study was a randomized clinical trial, which is the gold standard for evaluating interventions due to the lesser chance of bias. However, the split-mouth design may lead to the confounding of the treatment effects with carry-over effects. In the present study, a seven-day interval was respected between SRP sessions. Since the main outcome (pain) presented a quick response and reversibility with no chance of residual effects from the anesthetics after seven days, it is quite likely that the washout period was sufficient for excluding any influence of one treatment over another (carry-over effect). The residual effect of the pain experience, however, cannot be estimated (22). Another problem with the split-mouth design is the need for patients with symmetrical disease patterns, which can encumber the recruitment process. However, this was not a problem in the present study, since most of eligible participants met the inclusion criteria. The advantages of the split-mouth design are that fact that a paired analysis requires a smaller number of participants in comparison to parallel study groups (23) and the comparison of anesthesia in the same individual eliminates the effect of confounding variables, as each participant serves as his/her own control.

Although subgingival SRP was performed by different operators, this fact likely did not exert a substantial influence on the results, as the same operator always performed the procedures on the same individuals. Furthermore, each operator received detailed training prior to the onset of the study and all SRP procedures were monitored by two professionals experienced in the periodontics (RPA and FBZ).

Although the number of dropouts was not small, it was similar to figures reported in other clinical trials involving the follow up of patients submitted to dental procedures. The number of patients who dropped out of the study after benzocaine $(n=3)$ or placebo $(n=3)$ was slightly higher than the number who dropped out after EMLA $(n=2)$ or the injectable anesthetic $(n=1)$. One third of the patients reported dropping out due to pain and it is plausible that the same occurred among those who did not return for the follow-up evaluation. However, as all patients received all treatments and no imbalance among the groups was found regarding the time of the dropouts, it is believed that this did not lead to selection bias. Our results were based on per-protocol analysis. It was performed an intention-totreat analysis because it could increase the risk of falsely claiming noninferiority (type I error), as it often leads to smaller observed treatment effects (24).

The topical anesthetic employed herein is known to have a short duration (15 to $20 \mathrm{~min}$ ) (15). However, mean operating time was nearly $30 \mathrm{~min}$ for each tooth. This longer operating time in comparison to that reported in other studies involving topical anesthetics (8-10), likely explains the higher pain scores. It should be pointed out that mean pocket depth and operating time were similar among the anesthetic modalities, which reduces the possibility of bias.

Eligible individuals were required to have four sextants in which at least two teeth had a PD and CAL $\geq 5$ $\mathrm{mm}$. Treatment was divided into two phases: treatment after treatment for gingivitis followed by treatment for periodontal disease. This approach allowed more time for the patients to learn good oral hygiene techniques and reduced the complexity of the subgingival treatment (25). Moreover, having least eight teeth (2 per sextant) with deep PD sites after gingivitis treatment was one of the eligibility criteria and the results demonstrate that deep sites can be effectively anesthetized with EMLA. Previous studies only included patients with VAS scores $\geq 30 \mathrm{~mm}$ upon periodontal probing $(9,10)$. No pain threshold was used in the present study in order to not restrict the findings to sensitive individuals, which would reduce the degree of external validity.

In conclusion, EMLA exhibited good effectiveness compared to the injectable anesthesia and performed better than 2\% benzocaine in SRP. Thus, EMLA is a viable anesthetic option during scaling and root planning, despite the frequent need for second application.

\section{Resumo}

Embora a anestesia injetável previamente a raspagem e alisamento subgengival (RASUB) reduza a dor, muitos pacientes relatam medo e amortecimento prolongado dos tecidos adjacentes. 0 objetivo deste estudo foi comparar o efeito de uma mistura eutética contendo $25 \mathrm{mg} / \mathrm{g}$ de lidocaina e $25 \mathrm{mg} / \mathrm{g}$ de prilocaina, lidocaina $2 \%$ injetável, benzocaina $2 \%$ tópica e um placebo na redução da dor durante a RASUB. Neste ensaio clínico randomizado, cego de boca dividida, trinta e dois pacientes que apresentavam mais que dois dentes com profundidade de sondagem e nível de inserção clínica $\geq 5 \mathrm{~mm}$, em no minimo 4 sextantes, foram randomicamente alocados em 4 grupos: $\mathrm{EMLA}^{\circledR}$, lidocaina $2 \%$ injetável, benzocaina $2 \%$ tópica ou placebo. Dor e desconforto foram mensurados usando uma Escala Visual Analógica (EVA) e Escala Verbal (EV). A satisfação dos pacientes com a anestesia foi determinada ao final de cada consulta. Análise de variância de medidas repetidas e regressão de Poisson foram usadas para análise. Os escores da EVA e EV não demonstraram diferenças estatisticamente significantes entre lidocaína injetável e $\operatorname{EMLA}^{\circledR}(p>0,05)$ e ambas as substâncias demonstraram significativamente melhor controle da dor comparadas a benzocaina $2 \%$ e placebo $(p<0,05) .93,7 \%$ e $81,2 \%$ dos indivíduos ficaram satisfeitos com o anestésico injetável e EMLA ${ }^{\circledR}$, respectivamente $(p=0,158)$. A insatisfação com a benzocaína e placebo foi aproximadamente 10 vezes maior do que com a anestesia injetável $(p=0,001)$. Em conclusão, o $E M L A^{\circledR}$ demonstrou um efeito equivalente no controle da dor quando comparado com a anestesia injetável e melhor do que a benzocaina 2\% em RASUB. Assim, o EMLA ${ }^{\circledR}$ é uma opção anestésica viável durante a raspagem e alisamento radicular, apesar da necessidade frequente de segunda aplicação.

\section{Acknowledgements}

The authors wish to thank the volunteers who participated in this study. 


\section{References}

1. Canakci V, Canakci CF. Pain levels in patients during periodontal probing and mechanical non-surgical therapy. Clin Oral Investig 2007;11:377-383.

2. Van Steenberghe $D$, Garmyn $P$, Geers $L$, Hendrickx $E$, Marechal $M$,

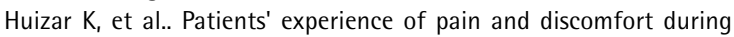
instrumentation in the diagnosis and non-surgical treatment of periodontitis. J Periodontol 2004;75:1465-1470.

3. Van Steenberghe D, Bercy P, De Boever J, Adriaens P, Geers L, Hendrickx $E$, et al.. Patient evaluation of a novel non-injectable anesthetic gel: a multicenter crossover study comparing the gel to infiltration anesthesia during scaling and root planing. J Periodontol 2004:75:1471-1478.

4. Milgrom P, Coldwell SE, Getz $T$, Weinstein P, Ramsay DS. Four dimensions of fear of dental injections. J Am Dent Assoc 1997;128:756766.

5. Saxena P, Gupta SK, Newaskar V, Chandra A. Advances in dental local anesthesia techniques and devices: An update. Natl J Maxillofac Surg 2013;4:19-24.

6. Chung JE, Koh SA, Kim TI, Seol YJ, Lee YM, Ku Y, et al.. Effect of eutectic mixture of local anesthetics on pain perception during scaling by ultrasonic or hand instruments: a masked randomized controlled trial. J Periodontol 2011;82:259-266.

7. Donaldson D, Gelskey SC, Landry RG, Matthews DC, Sandhu HS. A placebo-controlled multi-centred evaluation of an anaesthetic gel (Oraqix) for periodontal therapy. J Clin Periodontol 2003;30:171-175.

8. Jeffcoat MK, Geurs NC, Magnusson I, MacNeill SR, Mickels N, Roberts

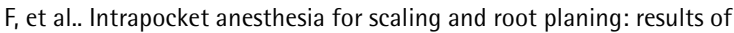
a double-blind multicenter trial using lidocaine prilocaine dental gel. J Periodontol 2001;72:895-900.

9. Magnusson I, Geurs NC, Harris PA, Hefti AF, Mariotti AJ, Mauriello SM, et al.. Intrapocket anesthesia for scaling and root planing in painsensitive patients. J Periodontol 2003;74:597-602.

10. Pandit N, Gupta R, Chandoke U, Gugnani S. Comparative evaluation of topical and electronic anesthesia during scaling and root planing. J Periodontol 2010;81:1035-1040.

11. Svensson P, Petersen JK, Svensson H. Efficacy of a topical anesthetic on pain and unpleasantness during scaling of gingival pockets. Anesth Prog 1994;41:35-39.

12. Derman $S H$, Lowden CE, Kaus $P$, Noack MJ. Pocket-depths-related effectiveness of an intrapocket anaesthesia gel in periodontal maintenance patients. Int J Dent Hyg 2014;12:141-144.

13. Derman $\mathrm{SH}$, Lowden $\mathrm{CE}$, Hellmich $\mathrm{M}$, Noack MJ. Influence of intra- pocket anesthesia gel on treatment outcome in periodontal patients: a randomized controlled trial. J Clin Periodontol 2014;41:481-488.

14. Canakci CF, Canakci V. Pain experienced by patients undergoing different periodontal therapies. J Am Dent Assoc 2007;138:1563-1573.

15. Friskopp J, Huledal G. Plasma levels of lidocaine and prilocaine after application of Oraqix, a new intrapocket anesthetic, in patients with advanced periodontitis. J Clin Periodontol 2001;28:425-429.

16. Herdevall BM, Klinge B, Persson L, Huledal G, Abdel-Rehim M. Plasma levels of lidocaine, o-toluidine, and prilocaine after application of 8.5 $g$ Oraqix in patients with generalized periodontitis: effect on blood methemoglobin and tolerability. Acta Odontol Scand 2003;61:230-234.

17. Vickers ER, Punnia-Moorthy A. A clinical evaluation of three topical anaesthetic agents. Aust Dent J 1992;37:267-270.

18. Meechan JG, Thomason JM. A comparison of 2 topical anesthetics on the discomfort of intraligamentary injections: a double-blind, splitmouth volunteer clinical trial. Oral Surg Oral Med Oral Pathol Oral Radiol Endod 1999;87:362-365.

19. Meechan JG, Winter RA. A comparison of topical anaesthesia and electronic nerve stimulation for reducing the pain of intra-oral injections. Br Dent J 1996;181:333-335.

20. Breivik H, Borchgrevink PC, Allen SM, Rosseland LA, Romundstad L, Hals EK, et al.. Assessment of pain. Br J Anaesth 2008;101:17-24.

21. Matthews DC, Rocchi A, Gafni A. Factors affecting patients' and potential patients' choices among anaesthetics for periodontal recall visits. J Dent 2001;29:173-179.

22. Hujoel PP. Design and analysis issues in split mouth clinical trials. Community Dent Oral Epidemiol 1998;26:85-86.

23. Lesaffre $E$, Philstrom B, Needleman I, Worthington H. The design and analysis of split-mouth studies: what statisticians and clinicians should know. Stat Med 2009;28:3470-3482.

24. Jones $B$, Jarvis $P$, Lewis JA, Ebbutt AF. Trials to assess equivalence: the importance of rigorous methods. BMJ 1996;313:36-39.

25. Gomes SC, Piccinin FB, Susin C, Oppermann RV, Marcantonio RA. Effect of supragingival plaque control in smokers and never-smokers: 6 -month evaluation of patients with periodontitis. J Periodontol 2007;78:1515-1521.
Received June 21, 2014 Accepted November 24, 2014 